\title{
Association of dietary sodium:potassium ratio with the metabolic syndrome in Chinese adults
}

\author{
Xiaocheng $\mathrm{Li}^{1} \dagger$, Baofu Guo ${ }^{2} \dagger$, Di Jin ${ }^{1}$, Yanli Wang ${ }^{1}$, Yun Jiang ${ }^{1}$, Baichun Zhu ${ }^{1}$, Yang Chen ${ }^{1}$, Liankai Ma ${ }^{1}$, \\ Han Zhou ${ }^{1}$ and Guoxiang Xie ${ }^{1 *}$ \\ ${ }^{1}$ Department of Nutrition and Food Hygiene, Nanjing Municipal Center for Disease Control and Prevention, Nanjing, \\ Jiangsu Province 210003, People's Republic of China \\ ${ }^{2}$ Key Laboratory of Environmental Medicine and Engineering of Ministry of Education, Department of Nutrition and \\ Food Hygiene, School of Public Health, Southeast University, Nanjing 210003, People's Republic of China
}

(Submitted 19 December 2017 - Final revision received 2 April 2018 - Accepted 27 April 2018 - First published online 2 August 2018)

\section{Abstract}

Several epidemiological studies have investigated that $\mathrm{Na}$ or $\mathrm{K}$ intakes might be associated with the metabolic syndrome (MetS). However, little evidence has evaluated the association between Na:K ratio and the MetS. In this study, we assessed the association between the dietary $\mathrm{Na}: \mathrm{K}$ ratio and the MetS. The cross-sectional study was conducted among adults aged 18 years and older in Nanjing, using a multi-stage random sampling method, which resulted in a sample size of 1993 participants. Dietary Na and K intakes were assessed by 3 consecutive days of dietary recollection combined with condiments weighing method. Health-related data were obtained by standardised questionnaires, as well as physical examinations and laboratory assessments. The prevalence rate of the MetS was 36.5\% (728/1993). After adjusting for various lifestyle and dietary factors of the MetS, participants in the highest quartile of dietary Na:K ratio were at a higher risk of developing MetS $(\mathrm{OR}=1.602 ; 95 \%$ CI 1.090, 2.353) compared with those in the lowest quartile. Each 1-sD increase in dietary Na:K ratio was associated with a higher risk of prevalent MetS ( $\mathrm{OR}=1 \cdot 166 ; 95 \% \mathrm{CI}: 1 \cdot 018,1.336$ ). Among the components of the MetS, dietary Na:K ratio was positively associated with high blood pressure (quartile $3 v$. quartile 1: OR $=1.656 ; 95 \%$ CI 1.228, 2.256) and hypertriacylglycerolaemia (quartile $4 v$. quartile $:$ OR $=1.305 ; 95 \%$ CI 1.029, 1.655) in multivariate analysis. These results revealed that higher dietary Na:K ratio significantly increased the risk of the MetS in Chinese adults. Further studies are needed to verify this association.

Key words: Dietary intake: Sodium:potassium ratio: Metabolic syndrome: High blood pressure: Hypertriacylglycerolaemia

The metabolic syndrome (MetS) consists of several metabolic risk factors such as abdominal obesity, hypertension, insulin resistance, hyperglycaemia and dyslipidaemia ${ }^{(1)}$. Substantial evidence has indicated that the MetS increased the risk of vascular diseases, diabetes, stroke ${ }^{(2,3)}$, atherosclerotic $\mathrm{CVD}^{(4,5)}$ and so on. In recent years, because of its increasing prevalence and socio-economic burden, the MetS has received widespread attention ${ }^{(6)}$. A metaanalysis incorporating studies from 2005 to 2015 showed that the pooled prevalence of MetS was 24.5 (95\% CI 22.0, 26.9)\% in Mainland China ${ }^{(7)}$. According to the latest national study, the prevalence of the MetS has reached $33.9 \%$, which indicates that the MetS affects approximately 454 million adults in China ${ }^{(8)}$. Experimental and epidemiological studies have indicated that dietary factors could be important for determining the MetS ${ }^{(9,10)}$.

$\mathrm{Na}$ and $\mathrm{K}$ are important electrolytes that are necessary for normal cellular function. Because of increasing risks of hypertension $^{(11,12)}, \mathrm{CVD}^{(13,14)}$, obesity ${ }^{(15,16)}$ and the $\mathrm{MetS}^{(17)}$, high $\mathrm{Na}$ and low $\mathrm{K}$ intake has become a serious public health challenge worldwide. These two electrolytes have an inverse relation and intake imbalance in the human body. Dietary $\mathrm{K}$ intake can attenuate salt sensitivity and the pressor impacts of salt ${ }^{(18)}$. Regarding the biological interaction of $\mathrm{Na}$ and $\mathrm{K}$, some studies have suggested that $\mathrm{Na}: \mathrm{K}$ ratio is more strongly associated with blood pressure, and that it can lead to a higher risk of CVD compared with $\mathrm{Na}$ or K intake alone ${ }^{(12,13,19)}$. Several studies have examined the relationship between $\mathrm{Na}$ or $\mathrm{K}$ intake alone and the MetS risk, but the results were inconsistent ${ }^{(17,20-22)}$. Unfortunately, none of the population-based studies has examined the relationship between dietary Na:K ratio and MetS risk. Therefore, it is important to explore the ratio of these two electrolytes instead of exploring $\mathrm{Na}$ or $\mathrm{K}$ intake alone in the diets.

Therefore, this study aims to examine whether high dietary $\mathrm{Na}: \mathrm{K}$ ratio is an independent risk factor for the MetS, as well as its components.

\section{Abbreviation: MetS, metabolic syndrome.}

* Corresponding author: G. Xie, fax +86 258353 8336, email guoxiang_xie@sina.com.

$\dagger$ Both authors contributed equally to this work. 


\section{Methods}

\section{Study population and sampling strategy}

The data used in this study were derived from a part of the 5th Chinese national nutrition and health survey, which was conducted from 2010 to 2013. In this cross-sectional study, a stratified, multi-stage probability cluster sampling design was used to recruit participants who had lived in Nanjing city for at least 6 months. In the first stage, two rural sampling sites (Pukou and Lishui) and four urban sampling sites (Qinhuai, primary Baixia, Yuhua and Gulou) were randomly selected. In the second stage, six villages/communities were randomly selected in each site, using a probability-proportional-to-size sampling scheme. In each village/community, seventy-five households were further selected randomly. All the members in the households were invited to take part in the study. In addition, thirty households were interviewed for 3-d, 24-h dietary recalls, twenty-five households were interviewed for FFQ and twenty households were interviewed for instant food questionnaires. All family members aged 6 years and older were invited to contribute a fasting blood sample for measuring blood glucose, blood lipids and so on.

The survey was conducted between August and October in each year. Subjects younger than 18 years of age were excluded from this analysis. Initially, 5832 subjects (2680 men and 3152 women; 2782 households) were recruited, and 2272 adults (1077 men and 1195 women; 1062 households) completed the 3-d, 24-h dietary recalls. A total of 279 individuals did not have information on laboratory examination; finally, 1993 adults were included. Written consents were obtained from all participants. This study was approved by the Medical Ethics Committee of the Chinese Centre of Disease Control and Prevention.

\section{Demographic and socio-economic factors}

The demographic factors and health behaviours of participants were collected by trained interviewers through face-to-face interviews, including age, sex and highest educational level achieved (primary school or below, middle or junior school and high school or more), and per-capita annual household income was categorised into low ( $<20000$ Yuan/person), moderate (20 000-34 999 Yuan/person) and high ( $\geq 35000$ Yuan/person). The health behavioural variables included current smoking (never smoker or current smoker for the past 1 month), alcohol consumption (g alcohol/d) and physical activity. The types, frequency and amount of alcohol/wine consumption were also collected and then converted into the amount of pure alcohol (in g) consumed per day. Current drinking was defined as consuming more than $0 \mathrm{~g}$ of alcohol daily for the past 1 month. Physical activity was quantified as a metabolic equivalent of task minutes per week (MET-min/week), and then classified as low (<600 MET-min/week), moderate (600-2999 MET-min/ week) or high ( $\geq 3000$ MET-min/week).

\section{Assessment of dietary intake}

Dietary intake was assessed by 3 consecutive days of dietary recollection combined with condiments weighing method, including 2 weekdays and 1 weekend day. Participants were asked to recall all food content and quantities they had consumed during the past $24 \mathrm{~h}$. The foods included staple foods, vegetables, fruits, snacks and so on. Measuring tools such as food models, food volumes and containers were used to enhance recall and conduct to the estimation of an average portion size. In addition, home condiment consumption (including cooking salt, monosodium glutamate, soya sauce, vinegar, sauces and other saltcontaining condiments) and cooking oil in each household were recorded using a household food inventory weighing method on the same $3 \mathrm{~d}$. According to the ratio of individual energy intake:the energy intake of all family members, the percentage of the condiments and oil of each family member was calculated. Further, daily condiments consumption was calculated for each family member. Finally, the daily food consumption data of the participants were obtained by a combination of 3 consecutive days of dietary recollection with condiments weighing method. On the basis of these food consumption data, the nutrient contents of the diet, including total energy, $\mathrm{Na}$ and $\mathrm{K}$, were analysed and calculated using the Chinese Food Composition Table (2nd ed.) ${ }^{(23)}$.

\section{Anthropometric measures}

At each study site, body weight and height were obtained for each adult participant by trained staff using standard protocols to the nearest $0 \cdot 1 \mathrm{~kg}$ and $0 \cdot 1 \mathrm{~cm}$, respectively. BMI was computed as weight $(\mathrm{kg})$ divided by height square $\left(\mathrm{m}^{2}\right)$. Waist circumference (WC) was measured at the narrowest point between the inferior margin of the last rib and the iliac crest in a horizontal plane. After $5 \mathrm{~min}$ of rest in the sitting posture, blood pressure was measured twice with a mercury sphygmomanometer (Shanghai ShangDa Medical Instrument Co. Ltd) on the right upper arm of the subject and then averaged.

\section{Laboratory evaluation}

Antecubital vein blood samples after fasting for $10-12 \mathrm{~h}$ were collected into a 2-ml vacuum, lithium heparin anticoagulant tube and a 4-ml vacuum tube, respectively, and immediately centrifuged at $1500 \boldsymbol{g}$ for $10-15 \mathrm{~min}$. These blood samples were used to evaluate glucose levels $(\mathrm{mmol} / \mathrm{l})$, total cholesterol $(\mathrm{mmol} / \mathrm{l})$, TAG $(\mathrm{mmol} / \mathrm{l})$ and HDL-cholesterol $(\mathrm{mmol} / \mathrm{l})$. After a fasting venous blood sample was collected, each participant received a 75-g oral glucose tolerance test, except for those with a known diagnosis of diabetes.

The blood samples were analysed in the Medical Center for Physical Examination, Nanjing Centre of Disease Control and Prevention for fasting blood glucose, serum cholesterol, TAG, HDL- and LDL-cholesterol, using the Hitachi 7180 auto-analyzer (Hitachi).

\section{Definition of the metabolic syndrome}

According to the American Heart Association and the National Heart, Lung and Blood Institute scientific statement ${ }^{(24)}$, the MetS was defined as the presence of three or more of the following criteria: (1) central obesity, $W C \geq 90 \mathrm{~cm}$ in men and WC $\geq 80 \mathrm{~cm}$ in women, and this criterion of WC was appropriate 
for Asians ${ }^{(25)}$; (2) hyperglycaemia, fasting glucose level $\geq 5.56 \mathrm{mmol} / \mathrm{l}(100 \mathrm{mg} / \mathrm{dl})$ or on drug treatment with elevated blood glucose; (3) low HDL-cholesterol, HDL-cholesterol $<1.03 \mathrm{mmol} / \mathrm{l}(40 \mathrm{mg} / \mathrm{dl})$ in men and HDL-cholesterol $<1.3 \mathrm{mmol} / \mathrm{l}(50 \mathrm{mg} / \mathrm{dl})$ in women or on drug treatment for reduced HDL-cholesterol; (4) hypertriacylglycerolaemia, TAG level $\geq 1.7 \mathrm{mmol} / \mathrm{l}(150 \mathrm{mg} / \mathrm{dl})$ or on drug treatment for this lipid abnormality; and (5) high blood pressure, systolic blood pressure/diastolic blood pressure $\geq 130 / 85 \mathrm{mmHg}$ or on antihypertensive drug treatment for a history of hypertension.

\section{Statistical analysis}

The subjects of this study were divided into quartiles based on their Na:K ratio levels, and then the means of the MetS and its related components prevalence of the quartiles were compared. Dietary variables were adjusted for total energy intake by the residual method. Energy-adjusted $\mathrm{Na}: \mathrm{K}$ ratio values were divided into quartiles, with the lowest (quartile 1) as the reference group. Quartiles of $\mathrm{Na}: \mathrm{K}$ ratio 1 to 4 were $\leq 1.98$, $1.99-2.95,2.96-4.32$ and $\geq 4.33$. Linear regression analysis was used to test for trend across dietary $\mathrm{Na}: \mathrm{K}$ ratio quartiles. Differences among groups were tested by one-way ANOVA, and post hoc comparisons were performed using Bonferroni correction. Comparisons between categorical variables were performed with the $\chi^{2}$ test.

For further analysis, the association between dietary Na:K ratio and the risk of the MetS and its components was assessed using multivariate-adjusted logistic regression models. OR and 95\% CI were calculated. Three models were introduced. Model 1 was adjusted for age (continuous), sex, the ratio of TAG:HDL-cholesterol (not included in the MetS components analysis), BMI (continuous) and area of residence. Model 2 was further adjusted for education, physical activity, drinking and smoking status and the use of anti-diabetic, hypolipidaemic and antihypertension medications. Dietary factors such as total energy, carbohydrate and total fat were additionally adjusted for continuous variables in model 3 . Multiplicative interactions were tested by adding the interaction terms ( $\operatorname{sex} \times$ quartiles of dietary $\mathrm{Na}: \mathrm{K}$ ratio) using likelihood ratio test.

Statistical significance was considered when $P<0.05$ (twosided). All analyses were performed using the Statistical Package for Social Sciences software version 17.0 (SPSS Inc.).

\section{Results}

\section{General characteristics of the study population}

Among the 1993 enrolled individuals, 907 were men and 1086 were women. There were 728 participants diagnosed with Mets and the prevalence rate was $36.5 \%$. Participants with the MetS had significantly higher dietary $\mathrm{Na}: \mathrm{K}$ ratio than those without MetS (energy-adjusted means, 3.7 (SD 2.6) v. 3.3 (SD 2.1), respectively, $P<0 \cdot 01$ ). The general characteristics of subjects by quartiles and the potential confounding variables are shown in Table 1. Compared with the lowest quartile, participants in the highest quartile of dietary $\mathrm{Na}: \mathrm{K}$ ratio consumed more $\mathrm{Na}$, more fat and they had higher BMI level (all $P_{\text {for trend }}<0 \cdot 05$ ); they were also more likely to be daily smokers and farmers.

\section{Association of the sodium:potassium ratio with the metabolic syndrome and its components}

The prevalence rates of the MetS components were $48.4 \%$ for central obesity, $56.2 \%$ for high blood pressure, $32.6 \%$ for hypertriacylglycerolaemia, $22.2 \%$ for low HDL-cholesterol and $41.6 \%$ for hyperglycaemia. The prevalence rates of the MetS and its related components in relation to quartiles are shown in Fig. 1. The prevalence rates of the MetS, hyperglycaemia and hypertriacylglycerolaemia tended to increase with the dietary Na:K ratio quartiles (all $P_{\text {for trend }}<0 \cdot 05$ ). However, there were no obvious changes in high blood pressure, central obesity and low HDL-cholesterol. In addition, a direct relationship was shown between the mean dietary $\mathrm{Na}: \mathrm{K}$ ratio and the number of MetS components. In Fig. 2, the mean dietary Na:K ratio significantly increased with the number of MetS components after adjusting for age and sex $\left(P_{\text {for trend }}<0 \cdot 001\right)$.

Dietary Na:K ratio was independently and positively associated with the risk of prevalent MetS (Table 2). Compared with subjects in the lowest quartile of dietary $\mathrm{Na}: \mathrm{K}$ ratio, multivariateadjusted OR for the MetS in quartile 2, quartile 3 and quartile 4 were 1.495 (95\% CI 1.038, 2.151), 1.347 (95\% CI 0.927, 1.957) and 1.602 (95\% CI 1.090, 2.353), respectively, and a statistically significant dose-response relationship between dietary $\mathrm{Na}: \mathrm{K}$ ratio and the odds of the MetS was documented $\left(P_{\text {for trend }}=\right.$ 0.040). Each 1-sD increase in dietary Na:K ratio was still associated with a higher risk of prevalent MetS $(\mathrm{OR}=1 \cdot 166 ; 95 \% \mathrm{CI}$ $1 \cdot 018,1.336$ ). Furthermore, dietary Na:K ratio was positively associated with individual components of the MetS, especially high blood pressure, hyperglycaemia and hypertriacylglycerolaemia. Higher dietary Na:K ratio was associated with an increased risk of high blood pressure after adjusting for various factors in model 3 (quartile 3: OR $=1 \cdot 656$; $95 \%$ CI 1.228, 2.256), compared with the lowest quartile. The positive association between hyperglycaemia and dietary Na:K ratio was attenuated after adjusting for dietary factors. However, the positive association between hypertriacylglycerolaemia and dietary $\mathrm{Na}: \mathrm{K}$ ratio was enhanced after adjusting for dietary factors. No significant association was found between dietary $\mathrm{Na}: \mathrm{K}$ ratio and central obesity or low HDL-cholesterol.

The effects of the interaction of dietary Na:K ratio with sex on the association with the MetS and its components were not statistically significant (all $P_{\text {for interaction }}>0 \cdot 1$ ).

\section{Discussion}

To our knowledge, this is the first epidemiological study on the association between dietary $\mathrm{Na}: \mathrm{K}$ ratio and the risk of the MetS among Chinese adults. We found a significant dose-response relationship between dietary $\mathrm{Na}: \mathrm{K}$ ratio and the MetS, even after adjusting for possible confounding factors. Our study also identified that dietary $\mathrm{Na}: \mathrm{K}$ ratio significantly increased with the number of MetS components after adjusting for age and sex. It indicated that dietary Na:K ratio was an independent risk factor of the MetS, 
Table 1. Summary statistics of the study population divided into quartiles of the sodium:potassium ratio (Mean values and standard deviations and percentages)

\begin{tabular}{|c|c|c|c|c|c|c|c|c|c|c|}
\hline \multirow[b]{2}{*}{ Variables } & \multicolumn{2}{|c|}{ Quartile 1} & \multicolumn{2}{|c|}{ Quartile 2} & \multicolumn{2}{|c|}{ Quartile 3} & \multicolumn{2}{|c|}{ Quartile 4} & \multirow[b]{2}{*}{$P$} & \multirow[b]{2}{*}{$P_{\text {for trend }}$} \\
\hline & Mean & SD & Mean & SD & Mean & SD & Mean & SD & & \\
\hline \multicolumn{11}{|l|}{$\mathrm{Na}$ and $\mathrm{K}$ variablest } \\
\hline $\mathrm{Na}$ intake & 2300 & 1144 & $3816^{*}$ & 953 & $4966^{*}$ & 1202 & $7952^{*}$ & 4053 & $<0.001$ & $<0.001$ \\
\hline $\mathrm{K}$ intake & 1779 & $446 \cdot 1$ & $1539^{*}$ & 344 & $1405^{\star}$ & 351 & $1238^{*}$ & 364 & $<0.001$ & $<0.001$ \\
\hline $\mathrm{Na}: \mathrm{K}$ ratio & 1.4 & 0.5 & $2 \cdot 5^{\star}$ & 0.3 & $3 \cdot 6^{*}$ & 0.4 & $6 \cdot 4^{*}$ & 2.5 & $<0.001$ & $<0.001$ \\
\hline \multicolumn{11}{|l|}{ Health-related variables } \\
\hline Current smoking (\%) & $23 \cdot 8$ & & $24 \cdot 3$ & & $26 \cdot 5$ & & $32 \cdot 1$ & & 0.011 & 0.002 \\
\hline Current drinking (\%) & 25.9 & & $28 \cdot 5$ & & $28 \cdot 3$ & & $27 \cdot 3$ & & 0.774 & 0.640 \\
\hline Physical activity (\%) & & & & & & & & & 0.795 & 0.901 \\
\hline Low & $13 \cdot 5$ & & $14 \cdot 3$ & & $14 \cdot 7$ & & $14 \cdot 1$ & & & \\
\hline Moderate & $29 \cdot 8$ & & $25 \cdot 3$ & & $28 \cdot 3$ & & $26 \cdot 9$ & & & \\
\hline High & $56 \cdot 7$ & & $60 \cdot 4$ & & $57 \cdot 0$ & & $59 \cdot 0$ & & & \\
\hline \multicolumn{11}{|l|}{ Socio-demographic variables } \\
\hline Age (years) & $57 \cdot 1$ & $14 \cdot 2$ & $56 \cdot 4$ & $13 \cdot 4$ & $55 \cdot 4$ & $13 \cdot 8$ & $57 \cdot 2$ & $13 \cdot 8$ & 0.134 & 0.797 \\
\hline BMl $\left(\mathrm{kg} / \mathrm{m}^{2}\right)$ & $24 \cdot 4$ & 3.4 & $24 \cdot 3$ & $3 \cdot 3$ & $24 \cdot 4^{*}$ & $3 \cdot 2$ & $24 \cdot 8^{*}$ & 3.6 & 0.055 & 0.049 \\
\hline Female (\%) & $56 \cdot 7$ & & $55 \cdot 4$ & & 55.4 & & $50 \cdot 4$ & & 0.195 & 0.058 \\
\hline Rural (\%) & $30 \cdot 9$ & & $24 \cdot 7$ & & $28 \cdot 3$ & & $36 \cdot 3$ & & 0.001 & 0.029 \\
\hline Education (\%) & & & & & & & & & 0.003 & $<0.001$ \\
\hline Primary school or below & $26 \cdot 7$ & & $28 \cdot 7$ & & $29 \cdot 7$ & & $35 \cdot 1$ & & & \\
\hline Junior school & $34 \cdot 1$ & & $32 \cdot 9$ & & 34.9 & & $37 \cdot 1$ & & & \\
\hline High school/university & $39 \cdot 3$ & & 38.4 & & $35 \cdot 3$ & & $27 \cdot 7$ & & & \\
\hline Household income (yuan/year per person, \%) & & & & & & & & & $<0.001$ & 0.057 \\
\hline Low & $45 \cdot 6$ & & 48 & & $44 \cdot 8$ & & $50 \cdot 4$ & & & \\
\hline Moderate & 31.5 & & $34 \cdot 1$ & & $35 \cdot 1$ & & 31.9 & & & \\
\hline High & $18 \cdot 4$ & & $13 \cdot 1$ & & $15 \cdot 7$ & & $9 \cdot 0$ & & & \\
\hline No response & 3.6 & & $4 \cdot 8$ & & 4.4 & & $8 \cdot 6$ & & & \\
\hline \multicolumn{11}{|l|}{ Other dietary variablest } \\
\hline Energy intake (kJ/d) & 7862 & 2435 & $7364^{*}$ & 2255 & $7167^{\star}$ & 2242 & $7439^{*}$ & 2402 & $<0.001$ & $<0.001$ \\
\hline Energy intake $(\mathrm{kcal} / \mathrm{d})$ & 1879 & 582 & $1760^{\star}$ & 539 & $1713^{*}$ & 536 & $1778^{*}$ & 574 & $<0.001$ & $<0.001$ \\
\hline Carbohydrate intake (g/d) & 235.0 & 49.9 & $225 \cdot 1^{*}$ & $44 \cdot 7$ & $212 \cdot 0^{*}$ & $45 \cdot 0$ & $209 \cdot 6^{*}$ & $54 \cdot 0$ & $<0.001$ & $<0.001$ \\
\hline Fat intake $(g / d)$ & 63.9 & $20 \cdot 7$ & $71 \cdot 0^{*}$ & $18 \cdot 5$ & $77 \cdot 0^{*}$ & $18 \cdot 6$ & $80 \cdot 0^{\star}$ & 25.5 & $<0.001$ & $<0.001$ \\
\hline Protein intake $(\mathrm{g} / \mathrm{d})$ & $69 \cdot 0$ & $14 \cdot 7$ & $62 \cdot 1^{*}$ & $12 \cdot 1$ & $59 \cdot 0^{*}$ & $12 \cdot 3$ & $53 \cdot 0^{*}$ & $14 \cdot 7$ & $<0.001$ & $<0.001$ \\
\hline Fibre $(g / d)$ & $10 \cdot 7$ & $4 \cdot 7$ & $8 \cdot 8^{*}$ & 3.5 & $7 \cdot 7^{*}$ & 3.0 & $6 \cdot 6^{\star}$ & 2.7 & $<0.001$ & $<0.001$ \\
\hline Cereal and cereal products $(\mathrm{g} / \mathrm{d})$ & $230 \cdot 9$ & $71 \cdot 3$ & $230 \cdot 3$ & $67 \cdot 3$ & $215 \cdot 1^{*}$ & $65 \cdot 2$ & $217 \cdot 8^{\star}$ & 73.4 & $<0.001$ & $<0.001$ \\
\hline Vegetables $(g / d)$ & $298 \cdot 8$ & $169 \cdot 4$ & $268 \cdot 9^{*}$ & $135 \cdot 8$ & $244 \cdot 5^{\star}$ & $108 \cdot 0$ & $223 \cdot 0^{\star}$ & 111.3 & $<0.001$ & $<0.001$ \\
\hline
\end{tabular}

${ }^{*} P<0.05$ compared with quartile 1 .

$\dagger$ Dietary variables were total energy-adjusted values by residual method.

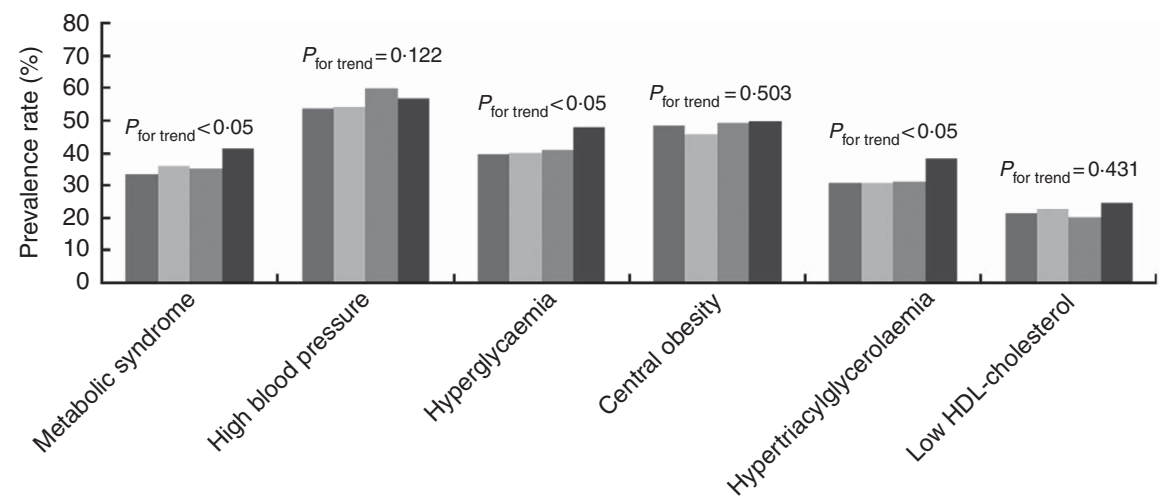

Fig. 1. Prevalence rates of the metabolic syndrome and its components in different dietary sodium:potassium ratio quartiles. $\square$, Quartile 1; $\square$, quartile 2; $\square$, quartile 3; $\square$, quartile 4.

and it offered a potentially modifiable strategy of the reduction of $\mathrm{Na}$ intake and increase of $\mathrm{K}$ intake to prevent the MetS.

$\mathrm{Na}$ and $\mathrm{K}$ are important electrolytes required by the body, and some studies have revealed the positive link between high $\mathrm{Na}$ or low $\mathrm{K}$ intake and metabolic disorders. Numerous mechanisms have been hypothesised to explain why high
$\mathrm{Na}$ intake contributes to metabolic disorders, with special emphasis on inadequate aldosterone suppression and increased mineralocorticoid receptor activation by factors other than aldosterone $^{(26,27)}$. K has been shown to play a role as an endothelium-derived hyperpolarising factor ${ }^{(28)}$ and stipulate nitric oxide to maintain endothelial function ${ }^{(29)}$. The impact of 
low $\mathrm{K}$ on metabolic disorders is mediated partly by the decrease of nitric oxide level and deterioration of endothelial function ${ }^{(30)}$, which may cause hyperglycaemia and insulin resistance ${ }^{(31)}$.

Previous studies have examined the association of $\mathrm{Na}$ or $\mathrm{K}$ intake alone with the MetS, although the results had been controversial $^{(17,20-22,32)}$. Rodrigues et $a l^{(21)}$ found that no differences were observed in urinary $\mathrm{Na}$ excretion in normotensive individuals, regardless of the presence of MetS. Ge et al. ${ }^{(17)}$ showed that urinary K excretion was not significantly associated with the risk of the MetS; however, high $\mathrm{Na}$ intake might be an independent risk factor for the MetS. Cai et al ${ }^{(32)}$ demonstrated a protective effect of adequate $\mathrm{K}$ intake on the MetS and obesity. This dispute was possibly explained by the fact that high $\mathrm{K}$ intake can attenuate salt sensitivity and the pressor impacts of salt ${ }^{(18)}$.

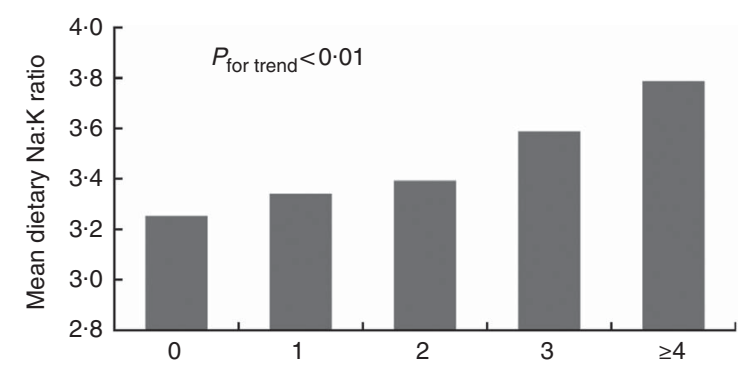

Fig. 2. Mean of dietary sodium:potassium ratio in the different number of the metabolic syndrome components $(\square)$ after adjusting for age and sex $(0, n 316$; 1, $n$ 449; 2, $n$ 499; 3, $n$ 437; $\geq 4, n$ 292).
Some studies have suggested that the Na:K ratio was more closely related to some chronic diseases than one mineral ${ }^{(13,19)}$. We considered that the $\mathrm{Na}$ : $\mathrm{K}$ ratio may be a sensitive indicator for assessing the risk of MetS, and the result requires more investigation. Therefore, we designed the study to observe the association between dietary $\mathrm{Na}: \mathrm{K}$ ratio and the risk of the MetS.

For the MetS components, our study showed a positive association between dietary $\mathrm{Na}: \mathrm{K}$ ratio and the risk of high blood pressure, which was consistent with previous studies $^{(11,12,33)}$. It has been reported that positive correlations between dietary Na:K ratio, the level of serum cholesterol and LDL-cholesterol and high $\mathrm{Na}: \mathrm{K}$ ratio may have a negative impact on lipid metabolism ${ }^{(34)}$. According to our results, individuals with higher $\mathrm{Na}: \mathrm{K}$ ratio were more likely to have hypertriacylglycerolaemia, even after adjusting for multiple risk factors. Interestingly, this positive association was enhanced after further adjusting for dietary factors (model 3). However, no significant association was observed between dietary Na:K ratio and the risk of low HDL-cholesterol. This controversy could be because of the fact that lipid levels are affected by other nutrients, such as fats, proteins and carbohydrates $^{(34)}$. Moreover, both $\mathrm{Na}$ and $\mathrm{K}$ intakes were closely tied to total energy intake ${ }^{(35)}$. Our dietary data were adjusted for total energy intake by the residual method. However, dietary data were not adjusted for total energy intake in this study ${ }^{(34)}$.

To date, no studies have been conducted to examine the association between dietary $\mathrm{Na}: \mathrm{K}$ ratio and blood glucose.

Table 2. Multivariate OR for the metabolic syndrome and its components according to quartiles of dietary sodium:potassium ratio ratio (Odds ratios and $95 \%$ confidence intervals)

\begin{tabular}{|c|c|c|c|c|c|c|c|c|c|c|}
\hline & \multirow[b]{2}{*}{ Quartile 1} & \multicolumn{2}{|c|}{ Quartile 2} & \multicolumn{2}{|c|}{ Quartile 3} & \multicolumn{2}{|c|}{ Quartile 4} & \multirow[b]{2}{*}{$P_{\text {for trend }}$} & \multicolumn{2}{|c|}{ 1-SD increase of $\mathrm{Na}: \mathrm{K}$ ratio } \\
\hline & & OR & $95 \% \mathrm{Cl}$ & OR & $95 \% \mathrm{Cl}$ & OR & $95 \% \mathrm{Cl}$ & & OR & $95 \% \mathrm{Cl}$ \\
\hline \multicolumn{11}{|c|}{ Metabolic syndrome } \\
\hline Model $1^{*}$ & 1 & 1.493 & $1.061,2 \cdot 101$ & 1.325 & $0.939,1.870$ & 1.454 & $1.031,2.052$ & 0.073 & 1.127 & $1.000,1.269$ \\
\hline Model $2 \dagger$ & 1 & 1.424 & $0.997,2.034$ & 1.288 & $0.901,1.841$ & 1.513 & $1.056,2 \cdot 168$ & 0.051 & 1.152 & $1.015,1.307$ \\
\hline Model 3ł & 1 & 1.495 & $1.038,2.151$ & 1.347 & $0.927,1.957$ & 1.602 & $1.090,2.353$ & 0.040 & $1 \cdot 166$ & $1.018,1.336$ \\
\hline \multicolumn{11}{|c|}{ High blood pressure } \\
\hline Model 1 & 1 & $1 \cdot 123$ & $0.844,1.495$ & 1.588 & $1 \cdot 189,2 \cdot 121$ & $1 \cdot 106$ & $0.829,1.474$ & 0.155 & 1.004 & $0.903,1.117$ \\
\hline Model 2 & 1 & $1 \cdot 107$ & $0.829,1.479$ & 1.591 & $1 \cdot 187,2 \cdot 131$ & $1 \cdot 121$ & $0.838,1.500$ & 0.128 & 1.007 & $0.904,1.121$ \\
\hline Model 3 & 1 & 1.145 & $0.853,1.536$ & 1.656 & $1.228,2.256$ & 1.201 & $0.881,1.637$ & 0.069 & 1.020 & $0.909,1.145$ \\
\hline \multicolumn{11}{|c|}{ Hyperglycaemia } \\
\hline Model 1 & 1 & 1.045 & $0.798,1.368$ & 1.140 & $0.872,1.491$ & 1.387 & $1.061,1.811$ & 0.013 & 1.120 & $1.017,1.233$ \\
\hline Model 2 & 1 & 1.024 & $0.779,1.345$ & $1 \cdot 107$ & $0.844,1.453$ & 1.383 & $1.054,1.813$ & 0.017 & 1.117 & $1.014,1.232$ \\
\hline Model 3 & 1 & 1.010 & $0.787,1.332$ & 1.044 & $0.787,1.385$ & 1.299 & $0.975,1.730$ & 0.071 & 1.092 & $0.985,1.209$ \\
\hline \multicolumn{11}{|c|}{ Central obesity } \\
\hline Model 1 & 1 & 1.000 & $0.687,1.456$ & 1.062 & $0.731,1.543$ & 0.971 & $0.664,1.419$ & 0.997 & 0.993 & $0.869,1.134$ \\
\hline Model 2 & 1 & 0.962 & $0.658,1.407$ & 1.035 & $0.710,1.509$ & 0.938 & $0.637,1.380$ & 0.857 & 0.989 & $0.864,1.131$ \\
\hline Model 3 & 1 & 0.964 & $0.656,1.416$ & 1.021 & $0.691,1.509$ & 0.909 & $0.604,1.367$ & 0.734 & 0.969 & $0.841,1.115$ \\
\hline \multicolumn{11}{|c|}{ Hypertriacylglycerolaemia } \\
\hline Model 1 & 1 & 1.041 & $0.788,1.375$ & 1.066 & $0.810,1.409$ & 1.330 & $1.014,1.745$ & 0.043 & 1.060 & $0.965,1.165$ \\
\hline Model 2 & 1 & 1.014 & $0.765,1.343$ & 1.045 & $0.791,1.381$ & 1.322 & $1.005,1.740$ & 0.048 & 1.061 & $0.965,1.167$ \\
\hline Model 3 & 1 & 1.066 & $0.801,1.419$ & 1.095 & $0.819,1.465$ & 1.305 & $1.029,1.655$ & 0.018 & 1.082 & $0.978,1.198$ \\
\hline \multicolumn{11}{|c|}{ Low HDL-cholesterol } \\
\hline Model 1 & 1 & 1.094 & $0.799,1.498$ & 0.891 & $0.647,1.228$ & 1.238 & $0.906,1.691$ & 0.382 & 1.048 & $0.939,1.169$ \\
\hline Model 2 & 1 & 1.078 & $0.784,1.481$ & 0.862 & $0.623,1.192$ & $1 \cdot 206$ & $0.880,1.653$ & 0.495 & 1.040 & $0.931,1.161$ \\
\hline Model 3 & 1 & $1 \cdot 124$ & $0.814,1.552$ & 0.922 & $0.658,1.292$ & 1.302 & $0.929,1.825$ & 0.267 & 1.071 & $0.952,1.204$ \\
\hline
\end{tabular}

* Model 1 was adjusted for age (continuous), sex, the ratio of TAG:HDL-cholesterol, BMI (continuous) and area of residence.

$\dagger$ Model 2 was further adjusted for education, physical activity, drinking and smoking status and the use of anti-diabetic, hypolipidaemic and antihypertension medications.

$\ddagger$ Model 3 was adjusted for total energy, carbohydrate and total fat intakes as continuous variables in addition to model 2. 
Our study found the positive association between dietary $\mathrm{Na}: \mathrm{K}$ ratio and hyperglycaemia, but the positive association was attenuated after further adjusting for dietary factors. This may be related to the effects of diet macronutrient composition on fasting glucose ${ }^{(36)}$.

In conclusion, our study found an independent and doseresponse association between dietary $\mathrm{Na}: \mathrm{K}$ ratio and MetS among Chinese adults in Nanjing, Jiangsu Province. These novel findings suggest the important role of reducing $\mathrm{Na}$ and increasing $\mathrm{K}$ intakes in diet and open new avenues for potential interventional targets to decrease the risk of MetS.

\section{Strengths and limitations}

To our knowledge, this may be the first epidemiology study that has focused on the association between dietary $\mathrm{Na}: \mathrm{K}$ ratio and the MetS. As a cross-sectional study of a relatively large sample, this study used the complex sampling method to explore the relationship of dietary $\mathrm{Na}: \mathrm{K}$ ratio and the MetS, adjusting for various potential confounders, such as age, sex, smoking, drinking, physical activity, BMI, the ratio of TAG:HDL-cholesterol, drug use and dietary factors in the multiple regression model; the overall results are relatively reliable.

The study has several limitations. First, the cross-sectional nature of our study makes it difficult to determine any causal relationship. In addition, 3 consecutive days of dietary recollection combined with condiments weighing method to assess the accuracy of the dietary $\mathrm{Na}$ and $\mathrm{K}$ intakes was not as good as the multiple 24-h urine collection method. Multiple 24-h urine collection method not only requires more funding but also adds a financial burden for the study participants. Furthermore, because of the high daily variability in $\mathrm{Na}$ and $\mathrm{K}$ excretion, when taking the effects of total energy into account, there were lower random errors in the method that we used to evaluate the $\mathrm{Na}$ and $\mathrm{K}$ intake, compared with spot or overnight urines, a single $24-\mathrm{h}$ dietary recall or urine collection ${ }^{(35)}$.

\section{Acknowledgements}

The authors acknowledge the contributions of the participants and investigators to the present study, from local Centers of Disease Control and Prevention, including Nanjing, Gulou, Qinhuai, primary Baixia, Yuhua, Pukou and Lishui, for their support in the survey implementation. The authors specially thank Prof. Fei Xu, Nanjing Municipal Center for Disease Control and Prevention, for his kind help in the article revision.

This study was financed by Nanjing Municipal Science and Technology Development Foundation (grant no. 201108006).

G. X. designed the study and was responsible for the review of the overall study. X. L. was in charge of the design of the study concept, data collection, interpretation, analysis and the first manuscript writing. B. G. was in charge of the study coordination, quality control and manuscript revision. D. J. was in charge of the study coordination, quality control and data analysis. Y. W., Y. J., B. Z., L. M., H. Z. and Y. C. conducted the research and analysed data.

The authors declare that there are no conflicts of interest.

\section{References}

1. Grundy SM, Hansen B, Smith SC Jr, et al. (2004) Clinical management of metabolic syndrome: report of the American Heart Association/National Heart, Lung, and Blood Institute/ American Diabetes Association conference on scientific issues related to management. Arterioscler Thromb Vasc Biol 109, 551-556.

2. Farias DR, Pereira AF \& Rosa G (2010) Metabolic syndrome in coronary artery and occlusive vascular diseases: a systematic review. Arq Bras Cardiol 94, 150-178.

3. Dekker JM, Girman C, Rhodes T, et al. (2005) Metabolic syndrome and 10-year cardiovascular disease risk in the Hoorn Study. Circulation 112, 666-673.

4. Agarwal S, Jacobs DR Jr, Vaidya D, et al. (2012) Metabolic syndrome derived from principal component analysis and incident cardiovascular events: the multi ethnic study of atherosclerosis (MESA) and health, aging, and body composition (Health ABC). Cardiol Res Pract 2012, 919425.

5. Wang J, Ruotsalainen S, Moilanen L, et al. (2007) The metabolic syndrome predicts cardiovascular mortality: a 13-year follow-up study in elderly non-diabetic Finns. Eur Heart $J \mathbf{2 8}$, $857-864$

6. O'Neill S \& O'Driscoll L (2015) Metabolic syndrome: a closer look at the growing epidemic and its associated pathologies. Obes Rev 16, 1-12.

7. Li R, Li W, Lun Z, et al. (2016) Prevalence of metabolic syndrome in Mainland China: a meta-analysis of published studies. BMC Public Health 16, 296.

8. Lu J, Wang L, Li M, et al. (2017) Metabolic syndrome among adults in China: the 2010 China Noncommunicable Disease Surveillance. J Clin Endocrinol Metab 102, 507-515.

9. Liu S, Song Y, Ford ES, et al. (2005) Dietary calcium, vitamin D, and the prevalence of metabolic syndrome in middle-aged and older U.S. women. Diabetes Care 28, 2926.

10. Esposito K, Marfella R \& Ciotola M (2004) Effect of a Mediterranean-style diet on endothelial dysfunction and markers of vascular inflammation in the metabolic syndrome: a randomized trial. JAMA 292, 1440-1446.

11. Zhang Z, Cogswell ME, Gillespie C, et al. (2013) Association between usual sodium and potassium intake and blood pressure and hypertension among U.S. adults: NHANES 20052010. PLOS ONE 8, 1002-1004.

12. Park J, Kwock CK \& Yang YJ (2016) The effect of the sodium to potassium ratio on hypertension prevalence: a propensity score matching approach. Nutrients $\mathbf{8}, 482$.

13. Cook NR, Obarzanek E, Cutler JA, et al. (2009) Joint effects of sodium and potassium intake on subsequent cardiovascular disease: the Trials of Hypertension Prevention follow-up study. Arch Intern Med 169, 32-40.

14. Yang Q, Liu T, Kuklina EV, et al. (2011) Sodium and potassium intake and mortality among US adults: prospective data from the Third National Health and Nutrition Examination Survey. Arch Intern Med 171, 1183-1191.

15. Ge Z, Zhang J, Chen X, et al. (2016) Are 24 h urinary sodium excretion and sodium:potassium independently associated with obesity in Chinese adults? Public Health Nutr 19, 1074-1080.

16. Jain N, Minhajuddin AT, Neeland IJ, et al. (2014) Association of urinary sodium-to-potassium ratio with obesity in a multiethnic cohort. Am J Clin Nutr 99, 992-998.

17. Ge Z, Guo X, Chen X, et al. (2015) Association between $24 \mathrm{~h}$ urinary sodium and potassium excretion and the metabolic syndrome in Chinese adults: the Shandong and Ministry of Health Action on Salt and Hypertension (SMASH) study. Br J Nutr 113, 996-1002. 
18. Morris RC Jr, Sebastian A, Forman A, et al. (1999) Normotensive salt sensitivity: effects of race and dietary potassium. Hypertension 33, 18.

19. Okayama A, Okuda N, Miura K, et al. (2016) Dietary sodiumto-potassium ratio as a risk factor for stroke, cardiovascular disease and all-cause mortality in Japan: the NIPPON DATA80 cohort study. BMJ Open 6, e011632.

20. Hoffmann IS \& Cubeddu LX (2009) Salt and the metabolic syndrome. Nutr Metab Cardiovasc Dis 19, 123-128.

21. Rodrigues SL, Baldo MP, de Sá Cunha R, et al. (2009) Salt excretion in normotensive individuals with metabolic syndrome: a population-based study. Hypertens Res 32, 906-910.

22. Shin D, Joh HK, Kim KH, et al. (2013) Benefits of potassium intake on metabolic syndrome: the fourth Korean National Health and Nutrition Examination Survey (KNHANES IV). Atherosclerosis 230, 80-85.

23. Yang Y, Wang G \& Pan X (2009) China Food Composition, 2nd ed. Beijing: Peking University Medical Press.

24. Grundy SM, Cleeman JI, Daniels SR, et al. (2005) Diagnosis and management of the metabolic syndrome. An American Heart Association/National Heart, Lung, and Blood Institute scientific statement. Circulation 112, 2735-2752.

25. Gu D, Reynolds K, Wu X, et al. (2005) Prevalence of the metabolic syndrome and overweight among adults in China. Lancet 365, 1398-1405.

26. Rossi GP, Belfiore A, Bernini G, et al. (2008) Body mass index predicts plasma aldosterone concentrations in overweightobese primary hypertensive patients. J Clin Endocrinol Metab 93, 2566.

27. Shibata S (2008) Modification of mineralocorticoid receptor function by Rac1 GTPase: implication in proteinuric kidney disease. Nat Med 14, 1370-1376.
28. Edwards G, Dora K, Gardener M, et al. (1998) $\mathrm{K}+$ is an endothelium-derived hyperpolarizing factor in rat arteries. Nature 396, 269-272.

29. Yang BC, Li DY, Weng YF, et al. (1998) Increased superoxide anion generation and altered vasoreactivity in rabbits on lowpotassium diet. Am J Physiol 274, 1955-1961.

30. Reungjui S, Pratipanawatr T, Johnson RJ, et al. (2008) Do thiazides worsen metabolic syndrome and renal disease? The pivotal roles for hyperuricemia and hypokalemia. Curr Opin Nephrol Hypertens 17, 470.

31. Reungjui S, Roncal CA, Mu W, et al. (2007) Thiazide diuretics exacerbate fructose-induced metabolic syndrome. I Am Soc Nephrol 18, 2724.

32. Cai X, Li X, Fan W, et al. (2016) Potassium and obesity/ metabolic syndrome: a systematic review and meta-analysis of the epidemiological evidence. Nutrients $\mathbf{8}, 183$.

33. Du S, Batis C, Wang H, et al. (2014) Understanding the patterns and trends of sodium intake, potassium intake, and sodium to potassium ratio and their effect on hypertension in China. Am J Clin Nutr 99, 334-343.

34. Bu SY, Kang MH, Kim EJ, et al. (2012) Dietary intake ratios of calcium-to-phosphorus and sodium-to-potassium are associated with serum lipid levels in healthy Korean adults. Prev Nutr Food Sci 17, 93-100.

35. Cobb LK, Anderson CA, Elliott P, et al. (2014) Methodological issues in cohort studies that relate sodium intake to cardiovascular disease outcomes: a science advisory from the American Heart Association. Circulation 129, 1173.

36. Gower BA, Goree LL, Chandlerlaney PC, et al. (2012) A higher-carbohydrate, lower-fat diet reduces fasting glucose concentration and improves $\beta$-cell function in individuals with impaired fasting glucose. Metabolism 61, 358. 